This is an Accepted Manuscript of an article published by Taylor \& Francis Group in Vehicle System Dynamics on Dec/10/2018, available online:

https://www.tandfonline.com/eprint/iUhNKzek/h5HnfqlyqEq/full 
Mehdi Ahmadian, $\mathrm{PhD}$

Center for Vehicle Systems and Safety, Virginia Tech, 3103 Commerce Street, Blacksburg, VA 24060, USA

Email: ahmadian@vt.edu

\title{
Achieving Anti-roll Bar Effect through Air Management in Commercial Vehicle Pneumatic Suspensions
}

\author{
Yang Chen, PhD \\ Research Scientist, \\ Center for Vehicle Systems and Safety, Virginia Tech, VA \\ Andrew W. Peterson, PhD \\ Senior Research Scientist \\ Center for Vehicle Systems and Safety, Virginia Tech, VA \\ Mehdi Ahmadian, PhD \\ Dan Pletta Professor and Director \\ Center for Vehicle Systems and Safety, Virginia Tech, VA
}

\begin{abstract}
This paper introduces the concept of managing air in commercial vehicle suspensions for reducing body roll. A conventional pneumatic suspension is re-designed to include higherflow air hoses and dual leveling valves for improving the dynamic response of the suspension to the body roll, which commonly happens at relatively low frequencies. The improved air management allows air to get from the air tank to the airsprings quicker, and also changes the side-to-side suspension air pressure such that the suspension forces can more readily level the vehicle body, much in the same manner as an anti-roll bar (ARB). The results of a multi-domain simulation study in AMESim and TruckSim indicate that the proposed suspension configuration is capable of providing balanced airflow to the truck's drive-axle suspensions, resulting in balanced suspension forces in response to single lane change and steady-state cornering steering maneuvers. The simulation results further indicate that a truck equipped with the reconfigured suspension experiences a uniform dynamic load sharing, smoother body motion (less roll angle), and improved handling and stability during steering maneuvers commonly occurring in commercial trucks during their intended use.
\end{abstract}

\section{Keywords}

Anti-roll bar, pneumatic, suspension, leveling valve, airspring, heavy truck, handling and stability, AMESim, TruckSim, multi-domain model 


\section{Introduction}

As compared to a passenger car, a heavy vehicle carries considerably larger loads with a higher center of gravity (CG), while having a limited track width due to regulations for motor vehicle dimensions [1]. As a result, the heavy truck is subjected to a larger body roll during cornering, leading to poor handling and increased rollover propensity, as compared with passenger cars. In order to resist the body roll in curves, a passive anti-roll bar can be used to increase the roll stiffness by twisting a U-shaped steel bar. Although the passive anti-roll bar helps suppress the body roll, it deteriorates the ride comfort in response to road irregularities [2]. To seek a means of improving the handling without sacrificing ride comfort, a number of active anti-roll bar mechanisms have been designed and studied. Zulkarnain et al. [2] applied a PID controller to adjust the resistance torque of an active anti-roll bar system. Significant improvements in body roll response and ride quality are observed in their simulation results for the vehicle with that active anti-roll. In a similar study, Cronje and Pieter [3] designed and tested an active anti-roll bar. Their testing results indicate improvements in body roll during dynamic handling tests without any significant influence on ride comfort. Darling and Hickson [4] investigated the application of an active anti-roll bar that was actuated by hydraulic actuators and controlled by an electric valve. They measured and evaluated the vehicle roll angle to rate the handling performance. Compared with a passive mechanism, their active anti-roll bar design improves the peak roll angle by approximately $80 \%$ during dynamic and steady-state steering maneuvers. Moreover, Cimba et al. [5] and Vu et al. [6] have studied and tested the performance of different hydraulic anti-roll bar designs. The systems discussed above, however, are not suitable for heavy trucks due to cost, complexity, and packaging. The objective of this 
paper is to introduce an anti-roll bar concept for heavy truck application, primarily using a slight modification to commonly-used components in pneumatic suspensions.

The pneumatic suspension has become more of a standard and essential piece of equipment for heavy truck applications. As a key advantage compared to a steel spring, the stiffness of the airspring is adjustable by changing the internal pressure. In that manner, many semiactive and active pneumatic suspensions have been developed to improve vehicle dynamics. For instance, Quaglia and Sorli [7], Porumanmilla et al. [8], and Nieto et al. [9, 10] have investigated the effect of air suspensions, with an auxiliary air tank that provides larger air mass within the suspension, in a manner where the air flow between the tank and airsprings is controlled through hoses or valves. Yin et al. [11] developed a pneumatic spring consisting of a double-acting pneumatic cylinder. The system is capable of providing independent control of stiffness and ride height by separately adjusting the pressure in each acting chamber, in order to better suit the road conditions and driver preferences. Deo and Suh [12] introduced a novel pneumatic suspension design in which the airspring stiffness is tuned by changing the effective volume via coupling the airsprings with multiple auxiliary volumes using a series of solenoid valves.

The practical application of the suggested adjustable pneumatic suspension systems in heavy trucks is limited considering cost, weight, reliability, and packaging issues. This paper proposes a pneumatic anti-roll configuration for heavy truck pneumatic suspensions that modifies the plumbing arrangement of a conventional pneumatic suspension. The proposed modifications are intended to improve the vehicle roll dynamics by better equalizing the suspension forces among the axles and side to side. 
To evaluate the improvement, multi-domain modeling is required to couple fluid dynamics of the pneumatic suspension with multi-body dynamics of the truck [13-16]. A detailed model of the pneumatic suspension is developed in AMESim that can capture the nonlinear characteristics of the airspring as well as the effect of the leveling-valve mechanism. Experiments are conducted to identify the pneumatic system properties, such as variations in effective area and volume of airspring, and leveling valve flow area, followed by validating the airspring and leveling valve models experimentally. The validated pneumatic suspension model is then integrated into the multi-body dynamic model of a semi-trailer truck through a co-simulation technique in order to evaluate the anti-roll performance of the suspension.

\section{Pneumatic suspension configuration}

Airsprings used in heavy trucks are typically connected with a load-leveling mechanism that consists of air tanks, check valves, hoses, and one or more leveling valves in order to maintain a nearly constant ride height in response to load variations. Figure 1a illustrates the configuration of an original equipment (OE) pneumatic suspension mounted on the tractor or the trailer's tandem axles. This type of pneumatic suspension, however, provides limited roll or pitch control during transient maneuvers [17-19]. Figure 1b shows the proposed modification to the $\mathrm{OE}$ pneumatic suspension arrangement by incorporating two leveling valves within a symmetric plumbing circuit. This arrangement yields a variable roll stiffness that allows for an independent side-to-side body control. This paper refers to the modified suspension as "balanced suspension." In contrast to the OE suspension, the balanced suspension employs larger air hoses and two leveling valves with larger flow capacity in order to reduce the resistance to air flow through the airsprings. Dynamically,

Page 5 of 30 
this enables the suspension to respond to dynamic inputs more quickly from the road or from driver maneuvers. It also allows the suspension on each side to respond to body rolls and road inputs independent of the other side. Additionally, the side-to-side symmetric arrangement results in a similar volume of air supplied into or dumped out of the airsprings. Although the balanced suspension is applicable to trucks with either single or tandem axles, only the latter is considered in this paper.

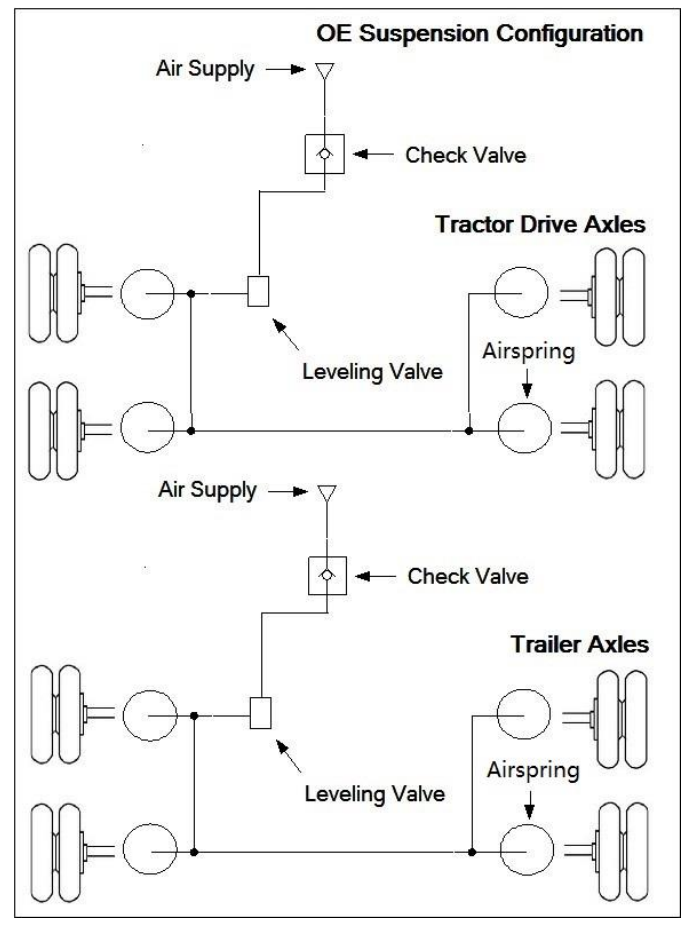

(a)

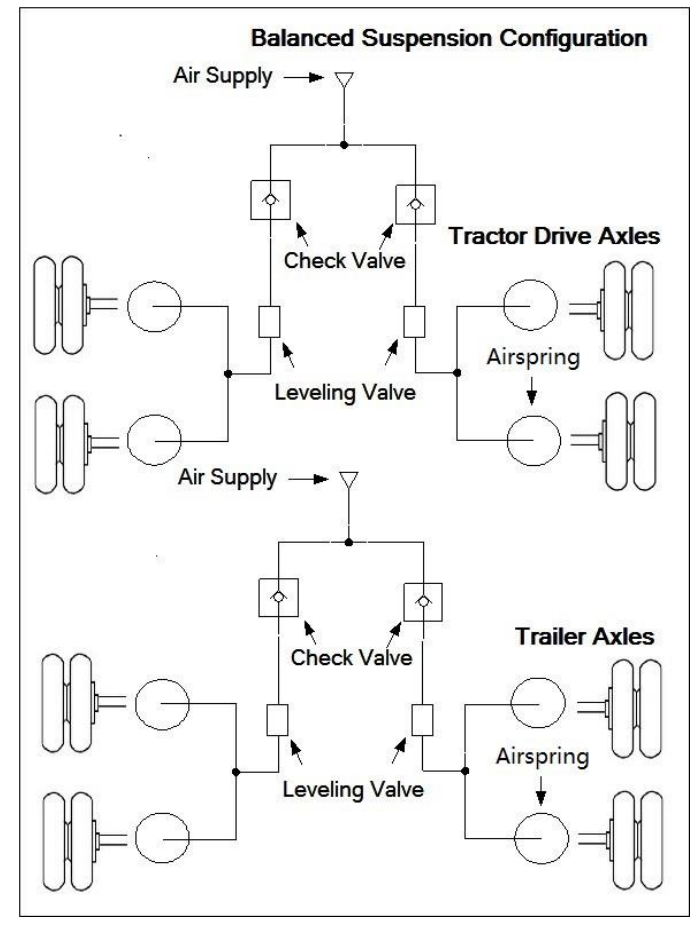

(b)

Figure 1. Plumbing arrangements on tractor and trailer tandem axles: original equipment (OE) suspensions (a), and balanced suspensions (b).

\section{Pneumatic suspension modeling and validation}

In this section, models of airsprings, leveling valves, and hoses are developed using AMESim. The airspring and leveling valve models are calibrated and validated with experimental data. The assumptions made for the models are [15]:

- The flow is one-dimensional 
- Air behaves as an ideal gas, with negligible kinetic energy

- Gravitation and inertial effects of the gas (air) are negligible

- Pressure and temperature are homogeneous in the airsprings and hoses

- The air tank supply pressure is constant

- Friction losses in $\mathrm{T}$ and $\mathrm{L}$ fittings are negligible

- Thermodynamic parameters of the airspring are constant

\subsection{Airspring model}

\subsubsection{Airspring model development}

According to the ideal gas law, the non-linear thermo-dynamical behavior of an airspring is governed by two equations of two-state variables, including pressure and temperature in the airspring $[20,21]$. The mass continuum equation provides:

$$
\dot{m}_{s}=\frac{d\left(\rho_{s} V_{S}\right)}{d t}=\dot{\rho}_{s} V_{s}+\rho_{s} \dot{V}_{s}=\frac{\dot{P}_{S} V_{s}}{R T_{s}}-\frac{P_{S} \dot{T}_{S} V_{S}}{R T_{s}{ }^{2}}+\frac{\dot{V}_{S} P_{s}}{R T_{s}}
$$

where $\dot{m}_{s}$ represents the rate of mass variation, $\rho_{s}$ is the air density in the airspring, $V_{s}$ is the airspring volume, $P_{S}$ and $T_{S}$ are the pressure and temperature of the air inside the airspring, and $R$ is the specific gas constant. Rearranging Equation (1) yields the pressure rate, a function of time:

$$
\dot{P}_{s}=\frac{P_{s}}{T_{s}} \dot{T}_{S}+\frac{R T_{s}}{V_{s}} \dot{m}_{s}-\frac{P_{s}}{V_{s}} \dot{V}_{S}
$$

Deriving temperature rate according to the First Law of Thermodynamics yields:

$$
\dot{U}_{s}=\dot{m}_{s} h_{i n}+\dot{Q}_{s}+\dot{W}_{s}=\dot{m}_{s} h_{i n}+k_{s} S_{s}\left(T_{\text {ext }}-T_{s}\right)-P_{s} \dot{V}_{s}
$$

where $\dot{U}_{s}, \dot{W}_{s}$, and $\dot{Q}_{s}$ are the time rates of the internal energy, the external work done by the airspring, and the heat exchange, respectively. The $T_{\text {ext }}$ is the ambient temperature, $h_{i n}$ is the enthalpy per mass unit, $S_{S}$ is the thermal exchange area calculated from measured 
geometric data, and $k_{s}$ is the thermal exchange coefficient determined through a comparison between simulation and experimental results [21]. The kinetic and potential energy of the air are negligible and not included; hence, the total energy of the airspring is equal to the internal energy as:

$$
\dot{U}_{s}=h_{s} \dot{m}_{s}+m_{s} \dot{h}_{s}-V_{s} \dot{P}_{s}-P_{s} \dot{V}_{s}
$$

where $h_{s}$ is the internal enthalpy per mass unit. Since we are assuming perfect gas, the internal enthalpy per mass unit, $h_{s}$, can be expressed as:

$$
h_{s}=c_{p} T_{s}=\frac{\gamma R}{\gamma-1} T_{S}
$$

where $\gamma$ is the specific heat ratio, and $c_{p}$ is the constant-pressure specific heat capacity. Substituting Equations (4) and (5) into Equation (3) yields:

$$
\frac{\gamma m_{s} R}{\gamma-1} \dot{T}_{S}-V_{s} \dot{P}_{S}=\dot{m}_{s} h_{i n}-\frac{\gamma R}{\gamma-1} T_{s} \dot{m}_{s}+k_{a s} S_{a s}\left(T_{e x t}-T_{s}\right)
$$

Combining Equation (2) into Equation (6) results in the following equation for the temperature rate:

$$
\dot{T}_{s}=\frac{\gamma-1}{R m_{s}}\left[\dot{m}_{s} h_{i n}-\frac{R T_{s}}{\gamma-1} \dot{m}_{s}+k_{a s} S_{a s}\left(T_{\text {ext }}-T_{s}\right)-P_{s} \dot{V}_{S}\right]
$$

Equations (2) and (7) are the differential equations that govern the dynamic behavior of the airspring and can be used for calculating the airspring pressure. The airspring force is then obtained as:

$$
F=\left(P_{s}-P_{a t m}\right) A
$$

where $P_{a t m}$ is the ambient pressure, and $A$ is the effective area. Differentiating Equation (8) with respect to suspension deflection yields the expression for airspring stiffness:

$$
K=\frac{d F}{d x}=\frac{A \gamma P_{s}}{m_{s}} \frac{\dot{m}_{s}}{\dot{x}}+\frac{A(\gamma-1) k_{a s} S_{a s}}{V_{s} \dot{x}}\left(T_{e x t}-\frac{V_{s} P_{s}}{R m_{s}}\right)-\frac{A \gamma P_{s}}{V_{s}} \frac{d V_{s}}{d x}+\left(P_{s}-P_{a t m}\right) \frac{d A}{d x}
$$


According to the equations above, an airspring model is developed in AMESim as shown in Figure 2. In AMESim, this component has rigid walls. In order to represent the change in volume resulting from radial expansion (bulging) of airspring side walls, another element (called "Normal Pneumatic Piston" in AMESim) is used to augment the change in volume according to our test data.

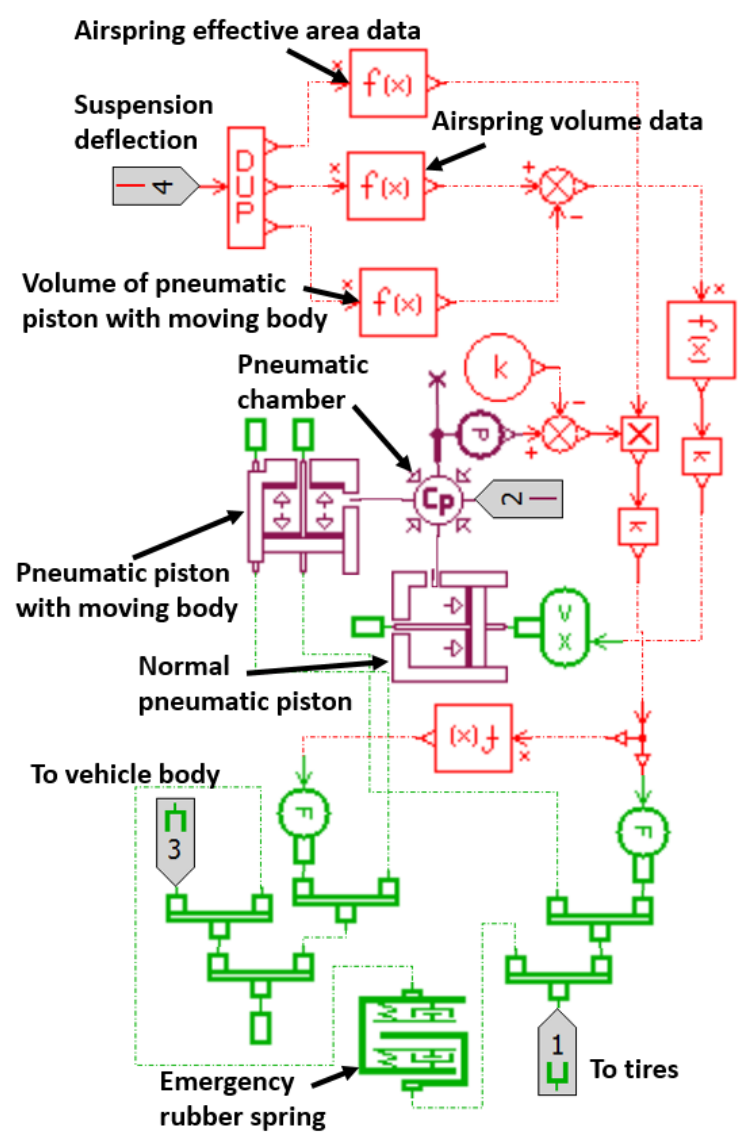

Figure 2. Airspring model developed in AMESim according to its governing equations.

Additionally, the purpose of the pneumatic chamber model is to calculate the pressure and temperature of the air inside the airspring according to Equations (2) and (7). The pressure is multiplied by the effective area (provided by another function block) to obtain the airspring force, as given in Equation (8). The forces are equally transmitted to the vehicle body (sprung mass) and axles (unsprung mass) through mechanical connectors, which are shown at the bottom of Figure 2. Two end-stops are used to simulate the internal bump Page 9 of 30 
stop and mechanism that prevents the airspring from overextending in rebound. Finally, it is important to include the changes in effective area and volume throughout the stroke, which are determined experimentally.

\subsubsection{Experimental characterization of the airspring}

To determine the effective area at different heights, the airspring is actuated by a shock dynamometer capable of creating different axial excitation patterns, as shown in Figure 3. The experiment is to compress the airspring from 15 to 8.5 inches while holding for 12 seconds in each 0.5 -inch increment. The experiment is carried out at a constant pressure of 15 and 20 psi. The effective area is then calculated by dividing the exerted force (measured by the actuator load cell) by the pressure of the airspring. This setup is also applicable for dynamic testing.

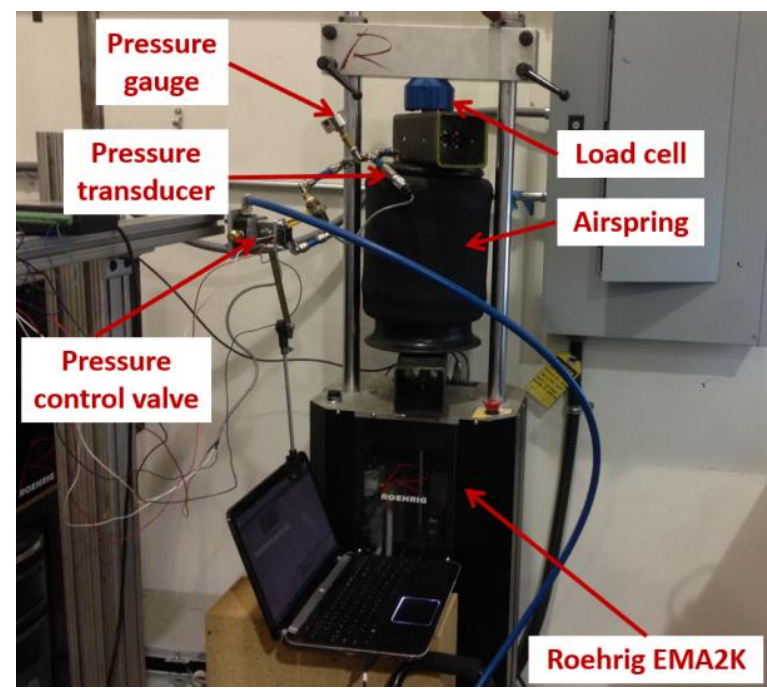

Figure 3. Experimental setup for measurement of the airspring's effective area.

Next, to define the change in volume with respect to height, the airspring is stretched to its near maximum height with a hoist and is then filled up with water, as shown in Figure 4a. As shown in Figure 4b, the water-filled airspring is placed in a test fixture that has a stationary bottom plate and a top plate that is able to move vertically only on four uprights. Page 10 of 30 
The top plate is then loaded with $936 \mathrm{lb}$ of weight, resulting in increased pressure within the airspring and bulging of the rubber sidewalls (bellow). A controlled amount of water is released from the airspring, and the resulting change in height is measured carefully in order to establish the relationship between airspring height and volume. Water is discharged in several steps until the airspring reaches its fully-compressed height (resting on an internal rubber bumper).

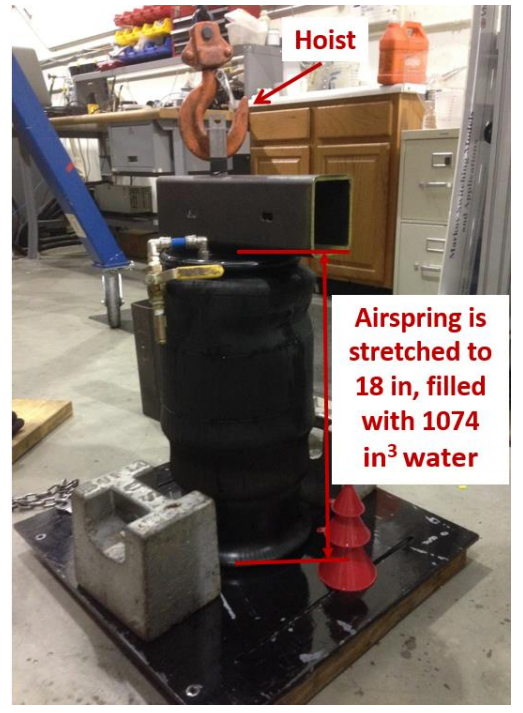

(a)

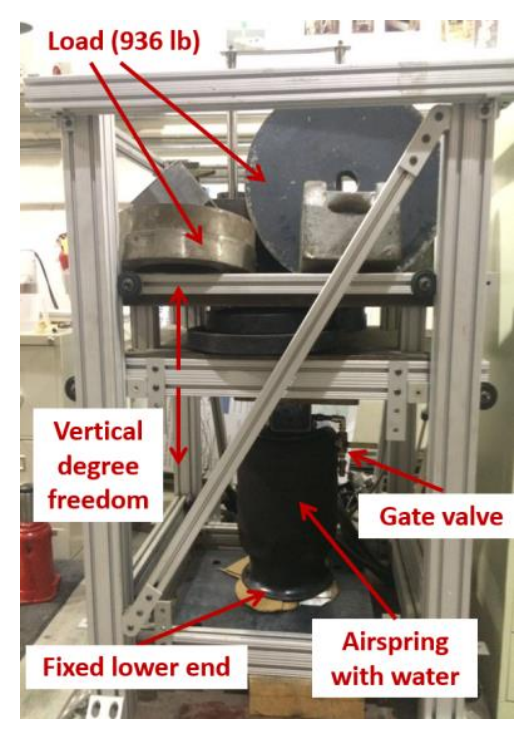

(b)

Figure 4. Experimental setup for measurement of the airspring's volume: filling up the stretched airspring with water (a); vertically loading the airspring (b).

Figure 5a shows the experimental results of the effective area at 15 and 20 psi. The effective area is mainly affected by the change in height and is nearly independent of pressure. This confirms the research results by Quaglia and Sorli [7] and Nieto et al. [9]. The results in Figure $5 \mathrm{~b}$ indicate that the airspring volume changes nearly linearly with height. 


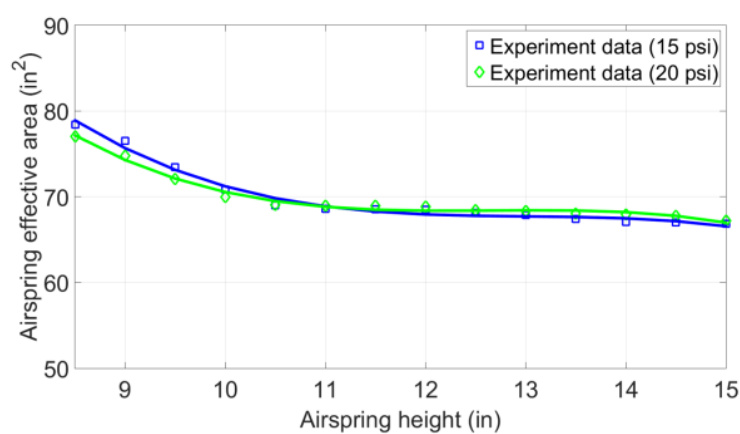

(a)

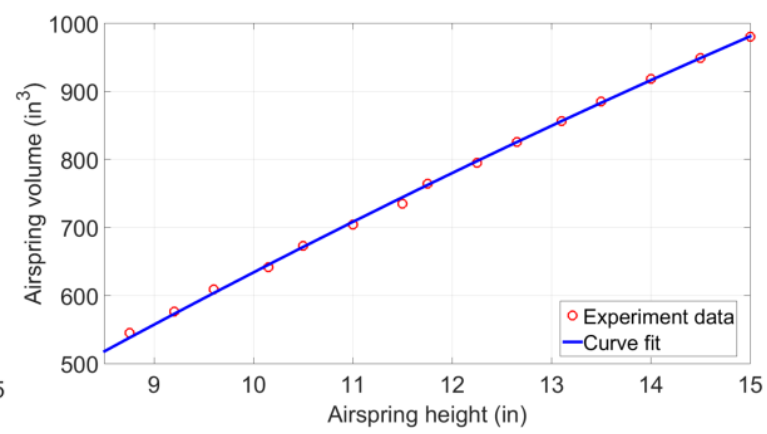

(b)

Figure 5. Experimental results for changes in airspring effective area (a) and volume (b) with respect to height.

\subsubsection{Experimental validation of the airspring model}

The test results in the previous section are used to provide the parameters needed for the airspring model in Figure 2. Figure 6 compares the measured airspring force with the model's results for a 1-inch sinusoidal excitation at $0.1,0.5$, and $1.0 \mathrm{~Hz}$. The airspring is initially set at 11 inches in height and 10 psi of internal pressure. The results for 0.1 and 1.0 Hz are shifted 200-lbf higher and lower than their actual values for comparison purposes. Figure 6 shows a good agreement between the simulated and experimental results, confirming the accuracy of the airspring model. A diminished hysteresis effect is observed as the excitation frequency increases due to lower heat transfer, as noted by the second term in Equation (9).

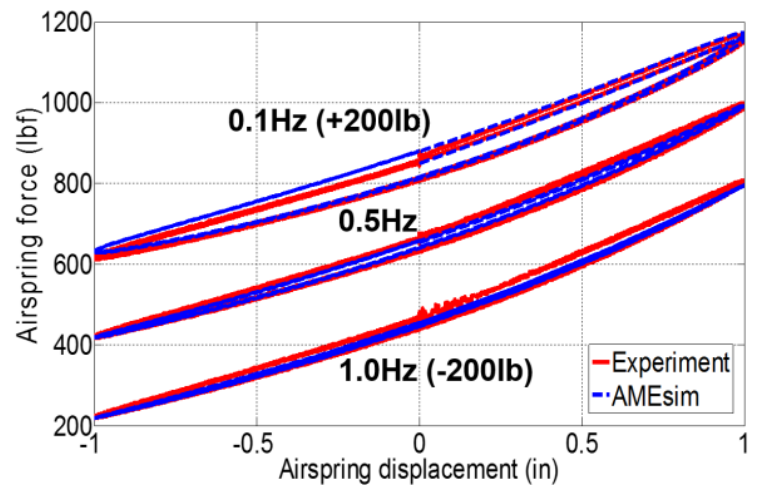

Figure 6. Comparison of airspring model with experimental data for airspring force response subjected to a 1-inch sinusoidal excitation at 0.1 (shifted up by $200 \mathrm{lb}$ ), 0.5 , and $1.0 \mathrm{~Hz}$ (shifted down by $200 \mathrm{lb})$. 


\subsection{Leveling valve model}

The leveling valve used in the truck pneumatic suspension is a mechanical valve that requires no complex wiring or calibration for operation. It is typically attached to the vehicle frame with a leveling arm connected to the axle by a control rod, as shown in Figure 7. This linkage arrangement allows the leveling valve to respond to the suspension deflection. If the suspension is compressed, the leveling arm rotates upward, supplying air to the airsprings until the suspension returns to its ride height. In rebound, the arm rotates in the opposite direction, and the air is discharged from the airsprings.

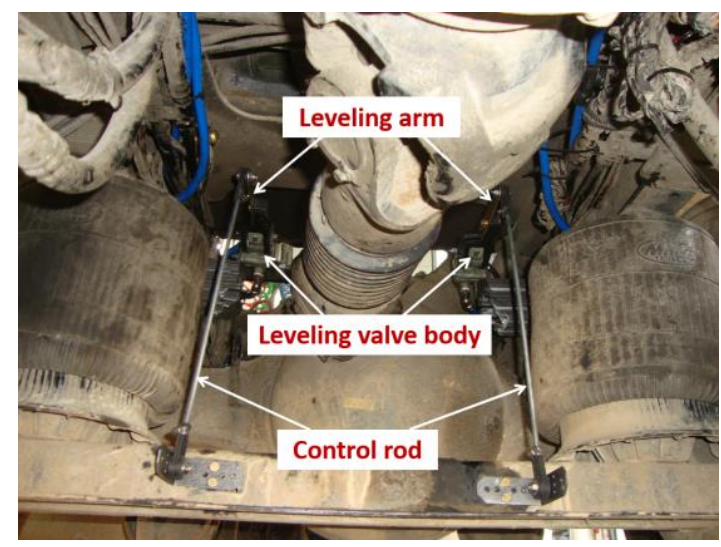

Figure 7. Leveling valve installation arrangement on tandem drive axles.

To calculate the airspring pressure in Equation (2), it is necessary to determine the mass flow rate across the leveling valve. The orifice flow principle is applied to calculate the mass flow rate at the leveling valve as:

$$
\begin{array}{ll}
\dot{m}_{L t}=S C_{q} P_{L i n} \sqrt{\frac{2 \gamma}{R T_{L i n}(\gamma+1)}}\left(\frac{2}{\gamma+1}\right)^{\frac{1}{\gamma-1}} & {\left[\frac{\mathrm{p}_{L t}}{\mathrm{p}_{L i n}} \leq\left(\frac{2}{\gamma+1}\right)^{\frac{\gamma}{\gamma-1}}\right]} \\
\dot{m}_{L t}=S C_{q} P_{L i n} \sqrt{\frac{2 \gamma}{R T_{L i n}(\gamma-1)} \sqrt{\left(\frac{P_{L t}}{P_{L i n}}\right)^{\frac{2}{\gamma}}-\left(\frac{P_{L t}}{P_{L i n}}\right)^{\frac{\gamma+1}{\gamma}}}} \quad\left[\frac{\mathrm{p}_{L t}}{\mathrm{p}_{L i n}}>\left(\frac{2}{\gamma+1}\right)^{\frac{\gamma}{\gamma-1}}\right]
\end{array}
$$

where $C_{q}$ is the flow coefficient to compensate for extra losses resulting from local friction, $S$ represents the geometric flow area, and $p_{L t}$ and $p_{L \text { in }}$ denote the downstream and Page 13 of 30 
upstream pressures, respectively [22]. As shown in Equations (10) and (11), at a certain pressure difference, the mass flow rate mainly depends on the flow area associated with suspension deflection. The flow area varies according to the rotation of the leveling arm. For each type of leveling valve, this relationship can be measured experimentally, as will be explained later. For this study, we conducted flow characterization tests for both leveling valves used in the balanced and $\mathrm{OE}$ suspensions. Considering that flow meters are commonly designed for steady-state flow measurements, we adopted an approach that enables measuring the transient flow rate in response to the movement of the leveling arm. The test employs a constant-volume air tank directly connected to the leveling valve by a hose with low resistance (short length and large inner diameter (ID)). By measuring the tank's pressure $\left(P_{a}\right)$ and rate of change of pressure $\left(\dot{P}_{a}\right)$, Equation (12) is used to calculate the mass flow rate for the tank $\left(\dot{m}_{a}\right)$, which is the same as the leveling valve mass flow rate $\left(\dot{m}_{L t}\right)$ due to the low flow resistance between the tank and leveling valve [23].

$$
\dot{m}_{L t}=\dot{m}_{a}=\frac{V_{a}}{k R T_{a 0}}\left(\frac{P_{a}}{P_{a 0}}\right)^{\frac{1-k}{k}} \dot{P}_{a}
$$

$P_{a}$ and $V_{a}$ are the air pressure and volume of the tank, respectively, $k$ is the polytropic exponent of air, and $P_{a 0}$ and $T_{a 0}$ are the initial pressure and temperature of the air inside the tank, respectively. 


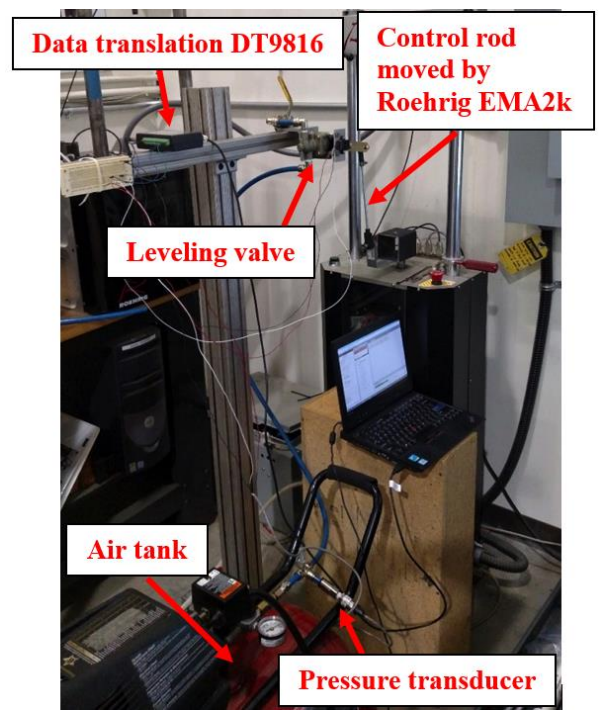

Figure 8. Test setup for flow characterization of a leveling valve.

Figure 8 shows the experimental setup, including a 33-gallon air tank connected to the upstream port of the leveling valve. The downstream port of the leveling valve is exposed to the atmosphere. The shock dynamometer (Roehrig EMA 2k dynamometer) is used to mimic the suspension deflection providing an accurate displacement input to the control rod rotating the leveling arm. All the pressure and rotation angle data of the leveling arm are collected by a data acquisition module (Data Translation DT9816). The experiment data of the mass flow rate and tank pressure are used in Equations (10) and (11) to calculate the flow area at various leveling arm rotation or suspension deflections. The three-position, three-port pneumatic valve in AMESim is applied to represent the leveling valve, in which the spool moves according to an interpolation of the flow area relationship, as shown in Figure 9. 


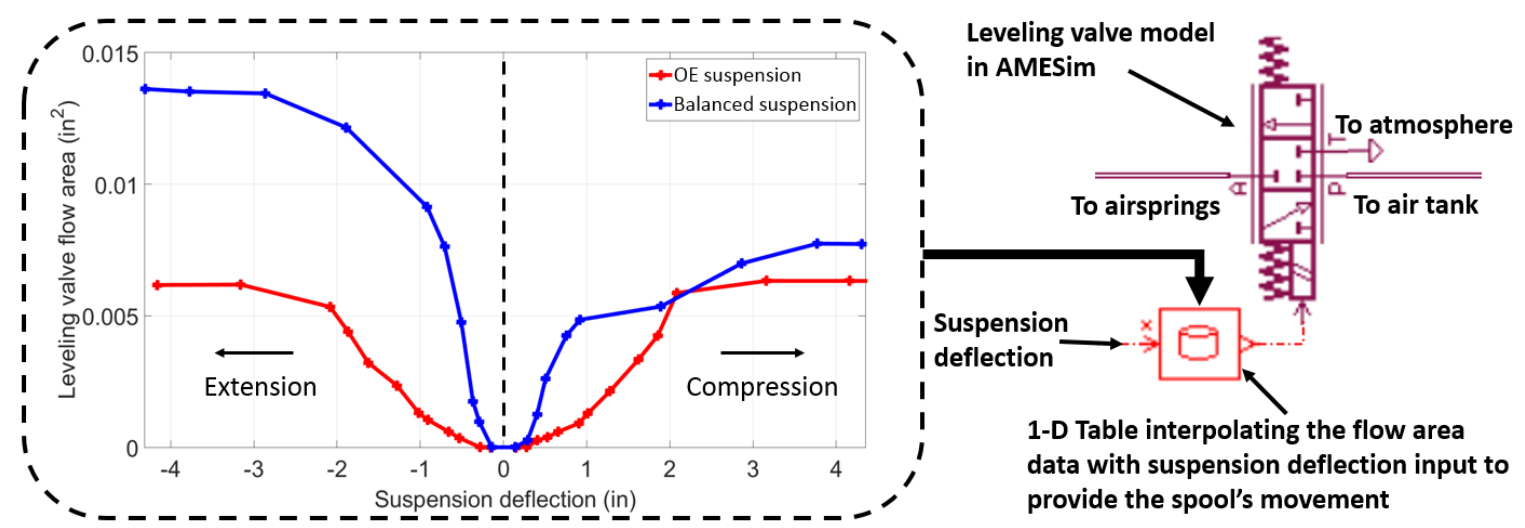

Figure 9. Leveling valve model in AMESim.

Figure 10 compares the leveling valve model results with experimental data for the mass flow rate for the balanced and OE suspensions. For each leveling valve, three experiments are conducted where the upstream pressure is set at 36,50 , and 65 psi while keeping the downstream port at atmospheric pressure. As shown in Figure 10, the non-linear characteristics of the leveling valve are well-predicted by the model at different pressures. A dead band exists around the neutral position, where no airflow exists, in order to prevent the leveling valve from chattering in response to small road disturbance. Compared with the OE leveling valve, there exists a larger flow-rate zone for the leveling valve in the balanced suspension, allowing for larger airflow in response to the vehicle body roll during steering maneuvers.

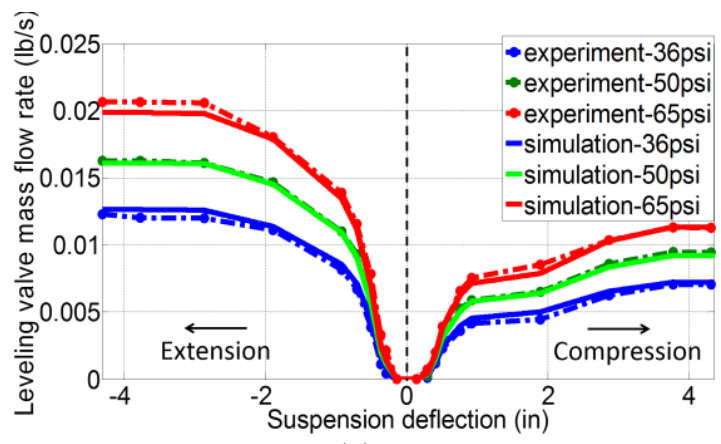

(a)

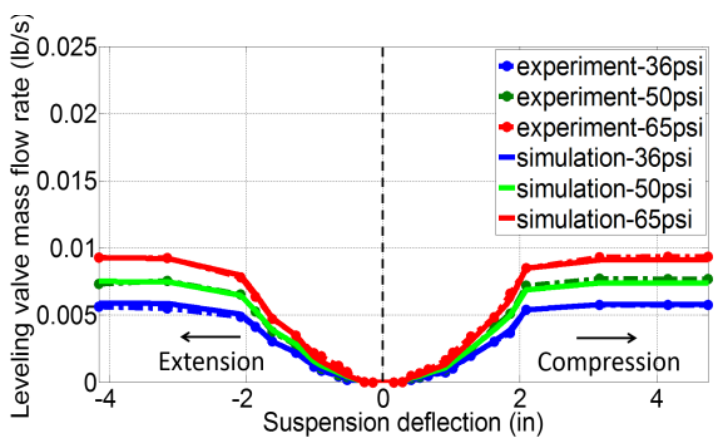

(b)

Figure 10. Comparison of the leveling valve model with experimental data, highlighting the effect of suspension deflection on the mass flow rate for balanced (a) and OE suspensions (b). 


\subsection{Hose model}

The hose connecting the air tank to the airsprings has two dominant effects on the dynamic response of the suspension system: dissipative and capacitive. The dissipative effect causes pressure losses that are directly proportional to the length and inversely proportional to the ID of the hose. The pressure losses also depend on the roughness of the inner wall, which is commonly neglected due to the smooth inner walls of the hose used in pneumatic suspensions. The internal diameter of the hose used in the balanced suspension is $70 \%$ larger than that in the OE suspension for a lower flow resistance. The compressibility of air and volume capacity of the hose results in a capacitive effect that attenuates the amplitude of the outlet airflow. The AMESim pipe model used here includes a cascade of dissipative and capacitive effects in order to simulate the transient flow within the hose.

\section{Integration with a semi-truck dynamic model}

Assembling the aforementioned component models in AMESim provides the OE and balanced suspension models, as shown in Figure 18 of Appendix A. To appraise the dynamic characteristics of the suspensions and their influences on truck dynamic behavior, the AMESim suspension models are integrated into multi-body dynamic models of tractorsemitrailers established in TruckSim. The TruckSim model applied in the study includes a $6 \times 4$ tractor hauling a 53-ft van-box trailer. Both tractor's and trailer's tandem axles use the AMESim pneumatic suspension models in place of the TruckSim's built-in suspension models. Tables 1 and 2 in Appendix B provide the parameters used for the pneumatic suspension and truck models, respectively [24].

Page 17 of 30 
Figure 11 shows a co-simulation scheme established in the study for merging the AMESim model with the TruckSim model through Simulink. Simulink is used to "patch" TruckSim and AMESim together such that the suspension force and displacement can properly flow between the two. Through Simulink, the AMESim module receives suspension deflections from the TruckSim module while sending airspring forces to the TruckSim module. An appropriately-adjusted error tolerance and a fixed time step for all modules are essential for the success of the co-simulation. Otherwise, an improper error tolerance can greatly amplify the error introduced at the mathematical integration process that occurs internal to the software.

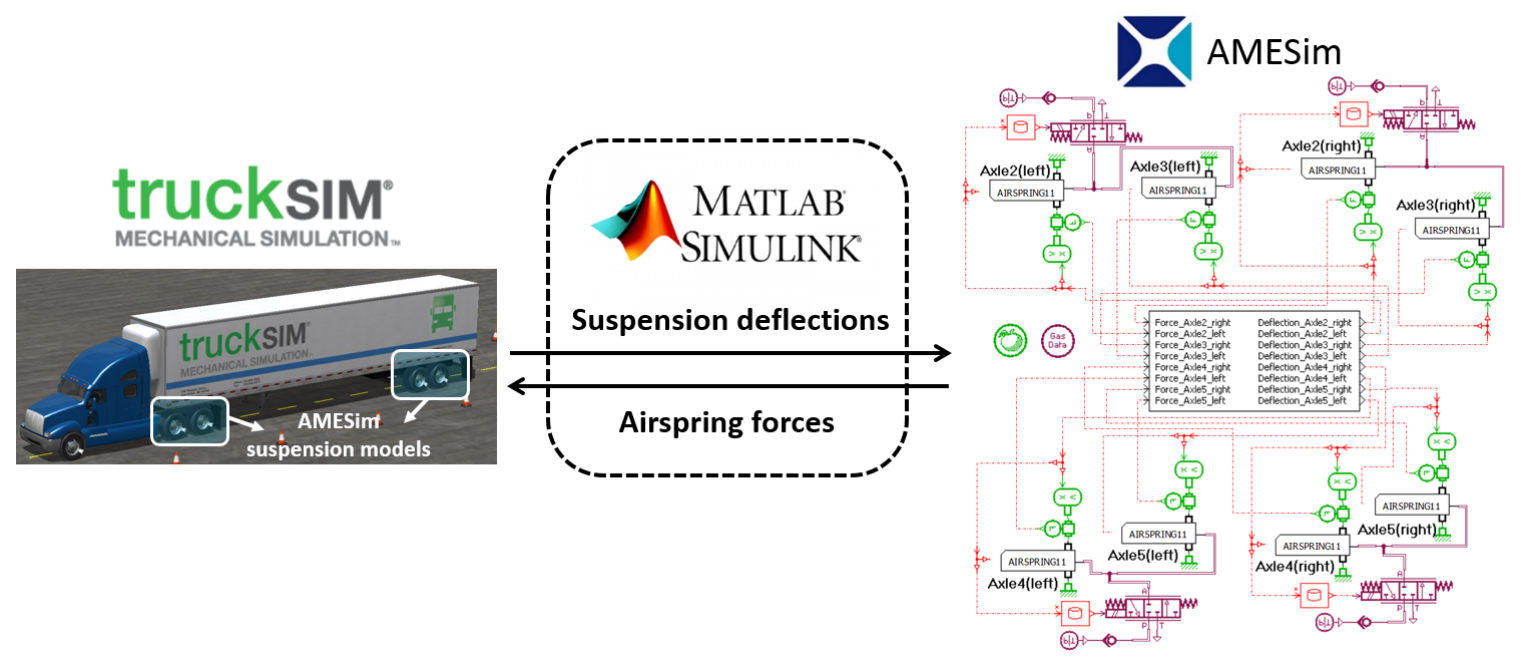

Figure 11. TruckSim-AMESim co-simulation scheme.

\section{Simulation maneuvers}

Single lane change and steady-state cornering, which are two of the critical actions that a truck driver frequently performs on highways, are adopted in this work for assessment of the truck pneumatic suspensions. Figure 12a presents the trajectory of the single lane change, where the performance of the truck is simulated at a constant speed of $35 \mathrm{mph}$. The path of the other simulation maneuver is shown in Figure 12b, including straight-ahead 
driving followed by entering a circle with a radius of $262 \mathrm{ft}$. The driving speed is $30 \mathrm{mph}$. In the simulation, the road is assumed to be perfectly level and smooth for both maneuvers.

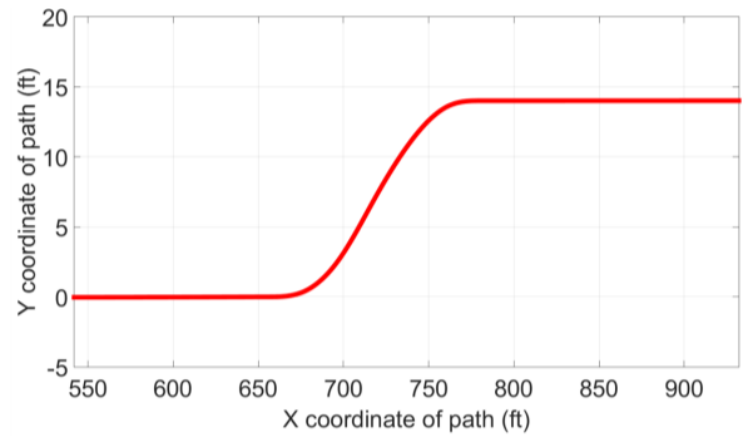

(a)

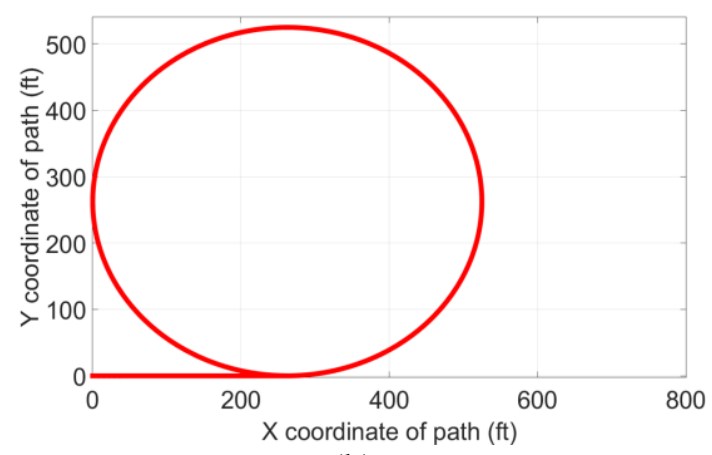

(b)

Figure 12. Paths of single lane change (a) and steady-state cornering (b).

\section{Simulation results and discussion}

In order to demonstrate improvements to roll dynamics that can be obtained via the reconfigured suspension, the roll response and suspension airflow dynamics of balanced suspensions are computed and compared with OE suspensions for single lane change and steady-state cornering maneuvers. This analysis is based on the truck model that is not equipped with a conventional anti-roll bar (ARB), thereby the simulation does not include any ARB roll stiffness contribution. Figures 13a-d show a comparison of roll angles between trucks equipped with the balanced and OE suspensions. The results show that balanced suspensions cause less roll in both tractor and trailer, mitigating body sway in the single lane change, and considerably diminishing body lean in the steady-state cornering. For the single lane change, the peak-to-peak roll angle is improved by nearly $8 \%$ for the tractor and trailer, while peak roll angles are lowered by as much as $17 \%$ during the steadystate cornering. A preliminary conclusion can be drawn that the reconfigured suspension (balanced suspension) functions similar to an anti-roll bar, helping to reduce the body roll. 


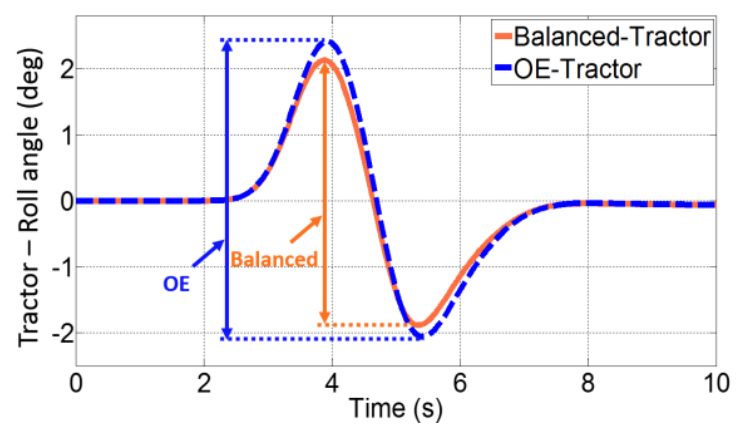

(a)

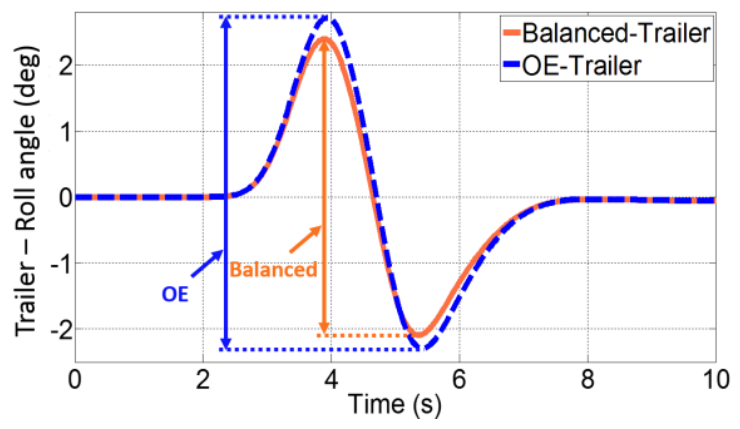

(c)

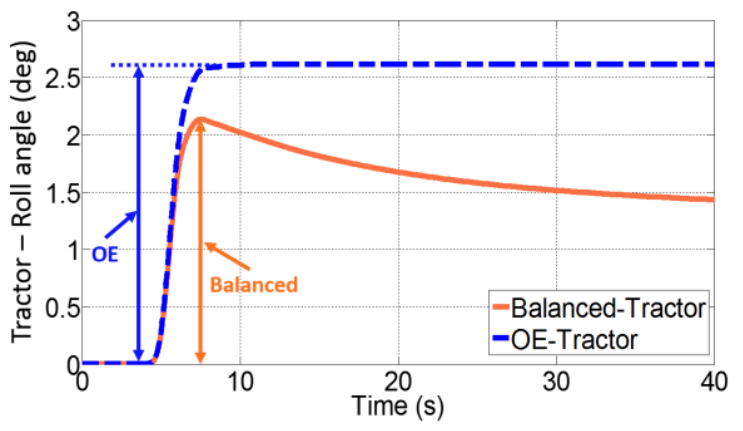

(b)

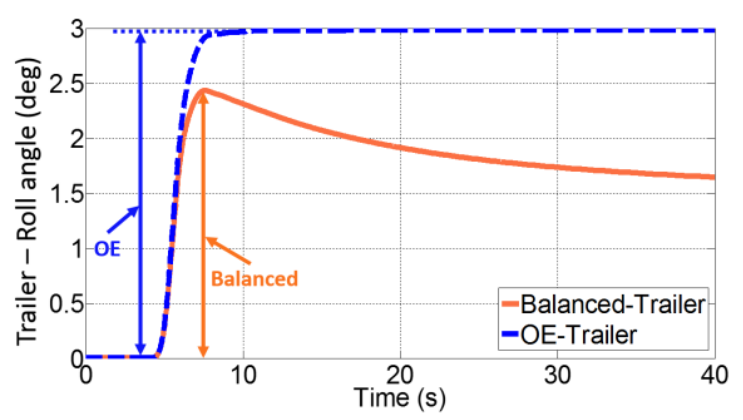

(d)

Figure 13. Time trace of roll angles of tractor and trailer for single lane change (a, c) and steadystate cornering $(b, d)$.

The results of the mass flow rates at the leveling valves are shown in Figures 14a-d for the balanced and OE suspensions. As the truck enters into cornering, the dual leveling valves of the balanced suspension always work in a side-to-side opposite manner, i.e. the jounce side supplies air to the airsprings, while the rebound side purges air from the airsprings. Consequently, the leveling valves are able to provide balanced airflow among the airsprings on tandem axles to better adjust for the body roll. In addition, higher air flow rates are observed for the balanced suspensions, as shown in Figure 14a-d, further enabling the suspension to more rapidly respond to the body roll. The high flow rates are attributed to inherent high-sensitivity characteristics of the leveling valve employed in the balanced suspensions, as shown in Figure 10. In contrast, the OE suspensions are not designed to 
quickly respond to the body dynamics resulting from steering maneuvers, by limiting the airflow through the leveling valve. It should be noted that although the leveling valve of the balanced suspension is designed to respond quickly to any suspension deflection caused by the body roll, there exists a time delay associated with the leveling valve (mainly due to a pneumatic dead band that is commonly designed in the valve). The time delay is emphasized in rapidly changing body rolls such as occurring during evasive maneuvers, sudden steering input, or a quick lane change. Such dynamics could potentially diminish the anti-roll control by the balanced suspension.

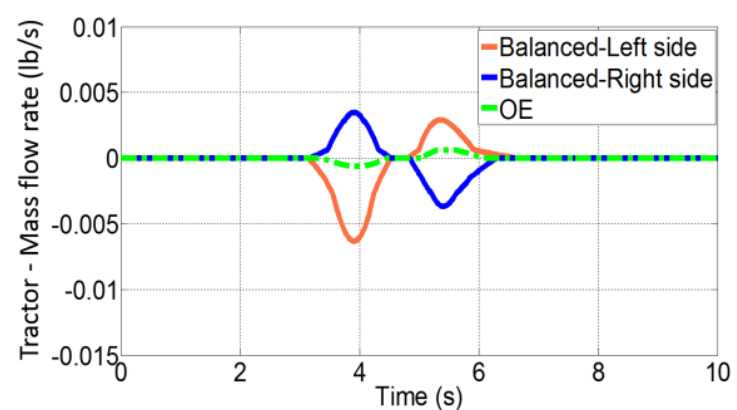

(a)

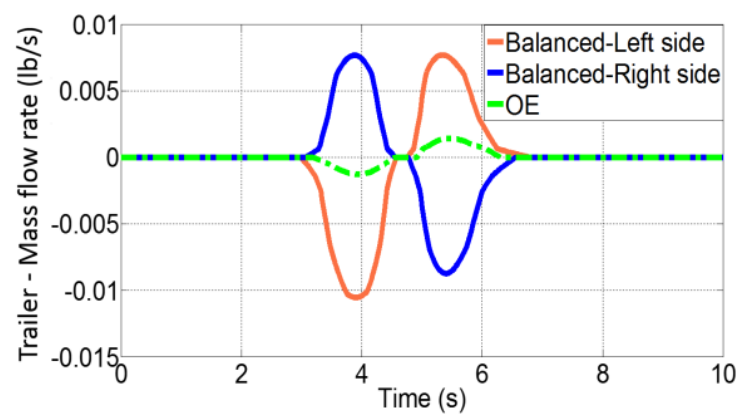

(c)

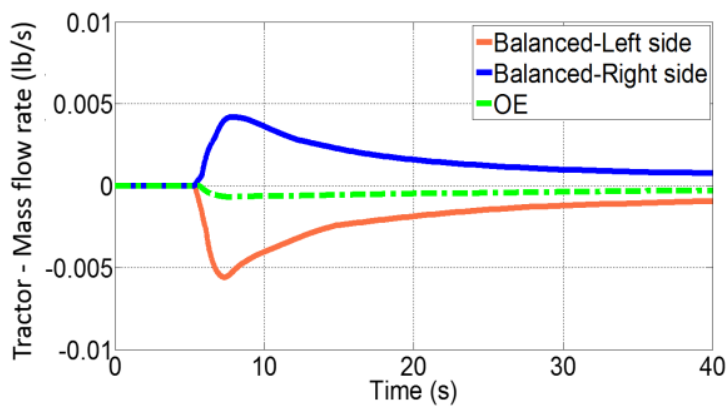

(b)

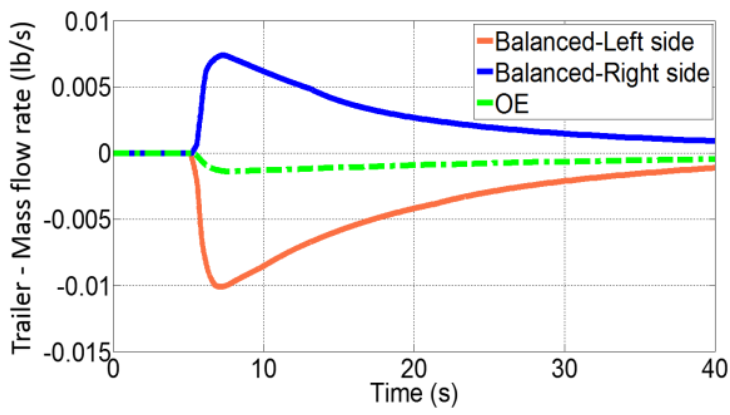

(d)

Figure 14. Time trace of the mass flow rate at the leveling valves for single lane change (a, c) and steady-state cornering (b, d).

Figures 15a-d compare the airspring pressures of balanced suspensions with those of $\mathrm{OE}$ suspensions for single lane change and steady-state cornering maneuvers. Only the trailer results are presented here due to the fact that their trends are similar to those of the tractors. A closer inspection of Figures $15 \mathrm{a}$ and $15 \mathrm{c}$ shows that the balanced suspension minimizes 
pressure variation between the front (4th) and rear (5th) axles, whereas there is more axleto-axle pressure variation for the OE suspension. Nearly equalized pressures distributed from the front to the rear axles are beneficial for equalizing dynamic load between the tandem axles, and for providing better body pitch control. Figures $15 \mathrm{a}-\mathrm{d}$ indicate that there are considerably larger side-to-side pressure differences for the balanced suspension, as compared with the OE suspension. The large pressure difference induces a set of restoring forces at the suspensions, which are transmitted to the sprung mass, resisting its roll motion much in the same manner as an anti-roll bar. Although larger suspension stiffness could cause higher body acceleration and lower ride comfort, in this case because it occurs over a short period of time, it does not have a diminishing effect on ride. In fact, we have noticed that the reduced body roll actually results in an improved subject evaluation of the ride by the driver and occupants.

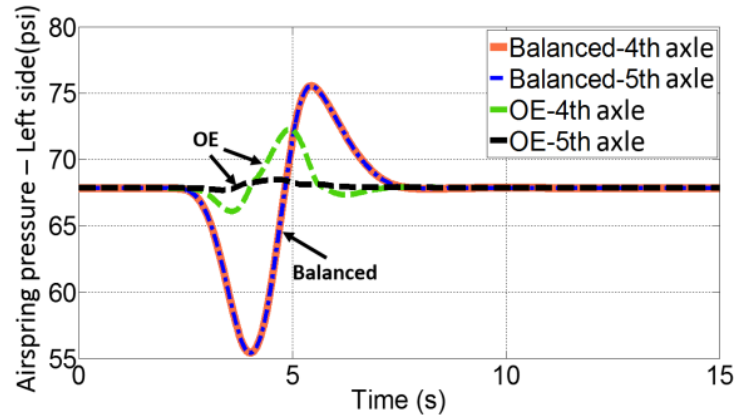

(a)

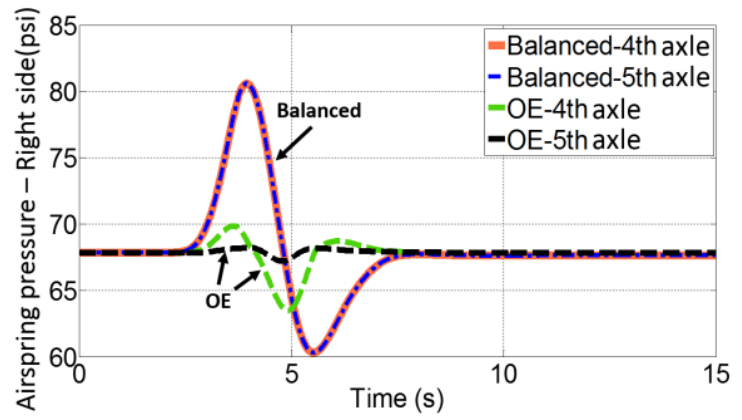

(c)

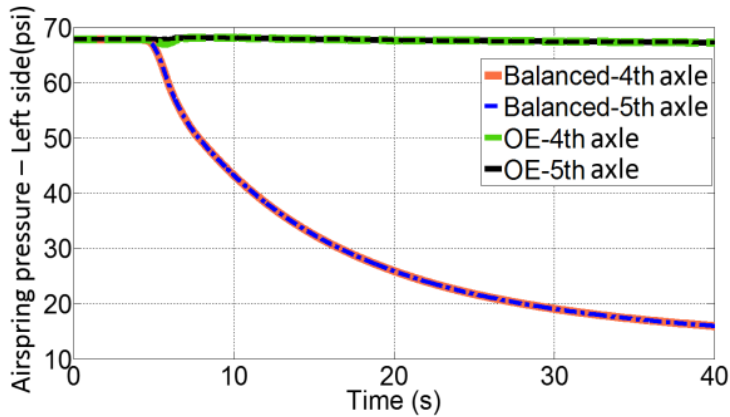

(b)

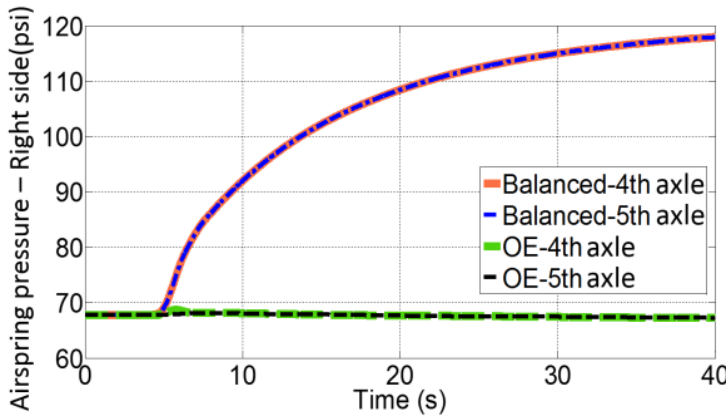

(d)

Figure 15. Time trace of airspring pressures on trailer axles for single lane change (a, c) and steady-state cornering $(b, d)$.

Page 22 of 30 
Figures 16 a-d show the change of the airsprings' anti-roll moment with respect to roll angle for the single lane change and steady-state cornering maneuvers. The balanced suspension provides a larger roll stiffness (anti-roll moment generated per unit of roll angle) than the OE suspensions in response to the roll of the vehicle body. The roll-plane hysteresis observed in Figures 16a and 16c is caused by vertical hysteresis characteristics of the pneumatic suspensions. The area of the roll-plane hysteresis is the total work by the suspensions during the single lane change maneuver. The balanced suspension provides positive work in the clockwise direction, as marked on the figures. This finding intensifies the certainty that the balanced suspension is able to stiffen the roll by using extra pneumatic energy (balanced airflows). In contrast, negative work is done for the OE suspension exhibiting an anti- or counter-clockwise hysteresis loop. This implies that during cornering, the OE suspension maintains a side-to-side air pressure that does not resist roll. In fact, it can add body roll caused by other forces. Taken to the extreme, the suspension forces can cause a vehicle that is rolled grossly to one side to rollover. This type of rollover is sometimes reported when the truck encounters a large ditch that tilts the body grossly to one side.

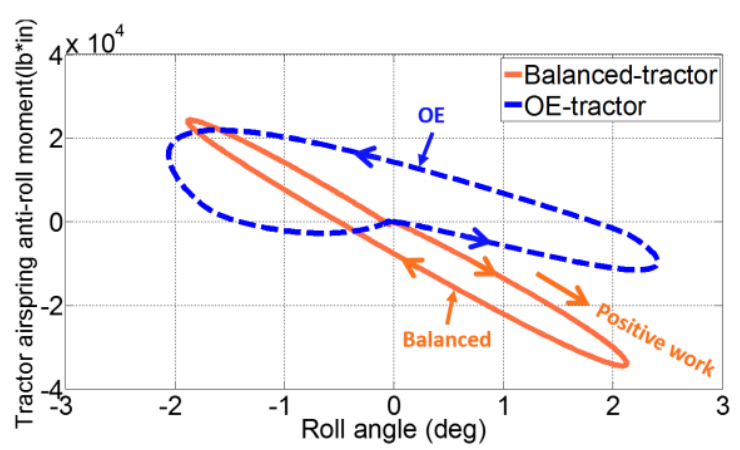

(a)

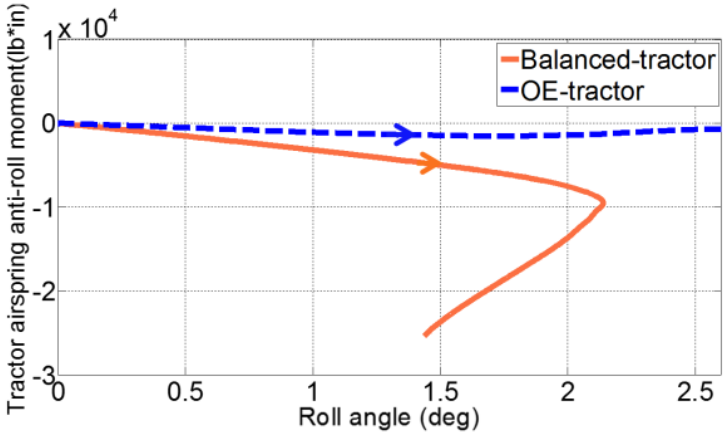

(b) 


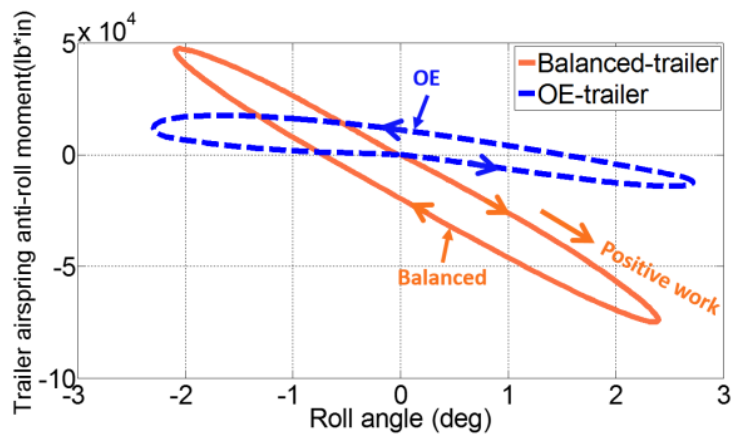

(c)

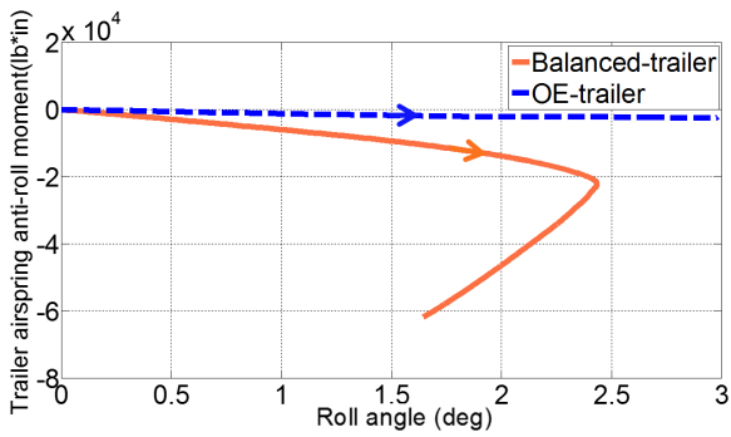

(d)

Figure 16. Anti-roll moment with respect to roll angle for single lane change (a, c) and steadystate cornering $(b, d)$.

Extensive simulations are executed to evaluate the suspension under various load conditions and driving speeds. The load conditions applied in the study include empty, half load (cargo load=12 tons), and full load (cargo load=23.3 tons). Figures 17 a-d show peakto-peak and peak values extracted from roll angles for single lane change and steady-state cornering. As shown in Figures $17 \mathrm{a}$ and $17 \mathrm{c}$, the balanced suspension results in improvements of $5 \%$ to $18 \%$ in the peak-to-peak values of the roll angle for the range of loads and speeds that are considered. For the steady-state cornering, peak roll angles of the truck with balanced suspensions are improved by $4 \%$ to $28 \%$. The improvement becomes more pronounced as the load and speed increase, as indicated in Figures 17b and 17d.

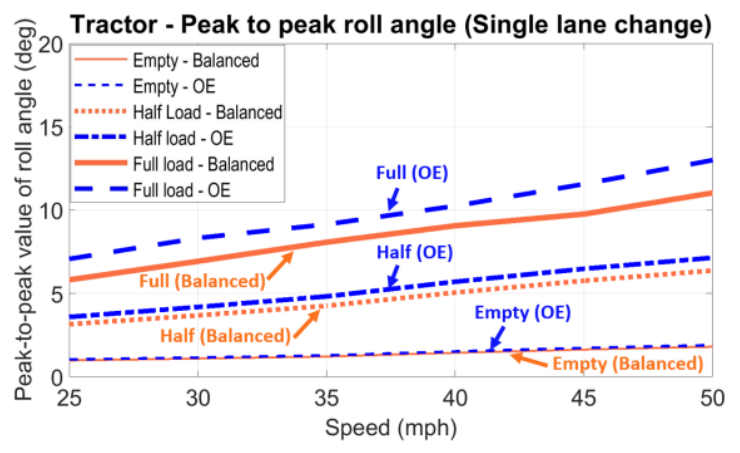

(a)

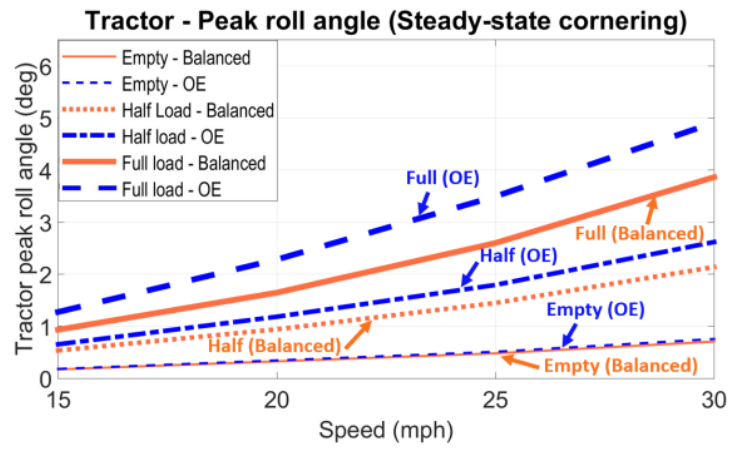

(b) 


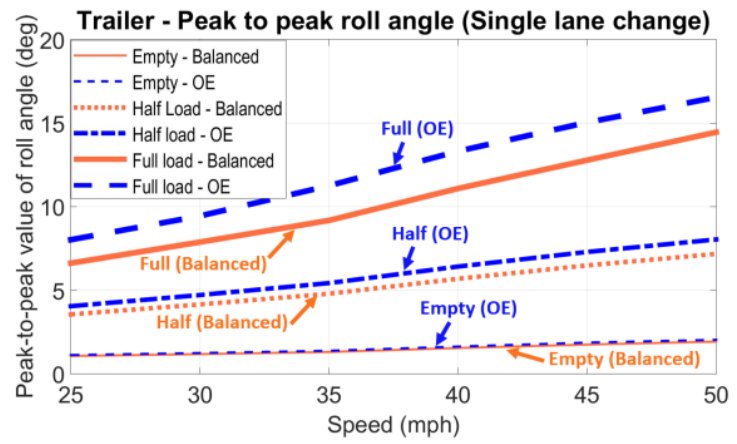

(c)

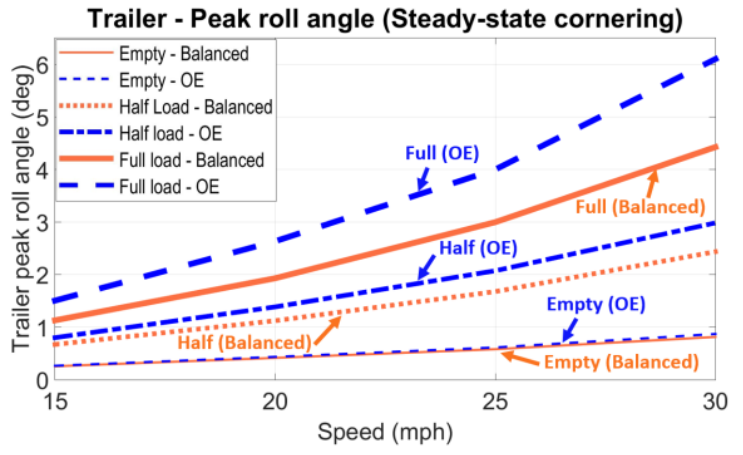

(d)

Figure 17. Summary results of peak-to-peak value of roll angle for single lane change (a, c) and peak roll angle for steady-state cornering $(b, d)$.

\section{Conclusions}

An investigation is performed for a proposed pneumatic anti-roll bar (referred to as "balanced suspension"), achieved through re-configuring a conventional pneumatic suspension for semi-trucks (referred to as "OE suspension"). A detailed model of the suspension's pneumatics, from the air tank to the airsprings, is developed in AMESim. Experiments are designed and conducted to provide calibration and validation of the airspring and leveling valve models. The validated pneumatic suspension model is then coupled with a multi-body dynamic model of the tractor and trailer in TruckSim, resulting in a rigorous multi-domain model used to perform an extensive set of simulations for the two types of suspensions. The simulation results indicate that the balanced suspension is able to provide a balanced airflow and well-regulated pressures at the airsprings during cornering, resulting in fairly even loads at the tandem axles and increased anti-roll moment to the vehicle body. The resulting anti-roll moment is able to mitigate the transient sway of the vehicle body in order to pull it back to a nearly leveled position in a sustained cornering maneuver, such as a long existing ramp. In summary, the study suggests that by 
dynamically managing the airflow, the suspension can serve as a pneumatic anti-roll bar to enhance handling and roll stability of semi-trucks.

\section{Declaration of conflicting interests}

The authors do not have any conflicts of interest to declare.

\section{References}

1. Cao, D., Song, X., and Ahmadian, M., "Editors' Perspectives: Road Vehicle Suspension Design, Dynamics, and Control,” Vehicle System Dynamics 49, no. 1-2, pp. 3-28, 2011.

2. Zulkarnain, N., Imaduddin, F., Zamzuri, H., and Mazlan, A. S., "Application of an Active Anti-roll Bar System for Enhancing Vehicle Ride and Handling," In Humanities, Science and Engineering (CHUSER), 2012 IEEE Colloquium on, pp. 260-265, IEEE, 2012.

3. Cronjé, P. H., and Pieter Sc. E., "Improving Off-road Vehicle Handling Using an Active Antiroll Bar," Journal of Terramechanics 47, no. 3, pp. 179-189, 2010.

4. Darling, J., and Hickson, L. R., "An Experimental Study of a Prototype Active Anti-roll Suspension System,” Vehicle System Dynamics 29, no. 5, pp. 309-329, 1998.

5. Cimba, D., Wagner, J., and Baviskar, A., "Investigation of Active Torsion Bar Actuator Configurations to Reduce Vehicle Body Roll," Vehicle System Dynamics 44, no. 9, pp. 719736, 2006.

6. Vu, T., Sename, O., Dugard, L., and Gáspár, P., "Enhancing Roll Stability of Heavy Vehicle by LQR Active Anti-roll Bar Control Using Electronic Servo-valve Hydraulic Actuators," Vehicle System Dynamics 55, no. 9, pp. 1405-1429, 2017.

7. Quaglia, G., and Sorli, M., "Air Suspension Dimensionless Analysis and Design Procedure," Vehicle System Dynamics 35, no. 6, pp. 443-475, 2001.

8. Porumamilla, H., Kelkar, A. G., and Vogel. J. M., "Modeling and Verification of an Innovative Active Pneumatic Vibration Isolation System," Journal of Dynamic Systems, Measurement, and Control 130, no. 3, 2008.

Page 26 of 30 
9. Nieto, A. J., Morales, A. L., Gonzalez, A., Chicharro, J. M., and Pintado, P., “An Analytical Model of Pneumatic Suspensions Based on an Experimental Characterization," Journal of Sound and Vibration, vol. 313, no. 1, pp. 290-307, 2008.

10. Nieto, A. J., Morales, A. L., Chicharro, J. M., and Pintado, P., "An Adaptive Pneumatic Suspension System for Improving Ride Comfort and Handling," Journal of Vibration and Control 22, no. 6, pp. 1492-1503, 2016.

11. Yin, Z. H., Khajepour, A., Cao, D., Ebrahimi, B., and Guo, K., “A New Pneumatic Suspension System with Independent Stiffness and Ride Height Tuning Capabilities," Vehicle System Dynamics 50, no. 12, pp. 1735-1746, 2012.

12. Deo, H., and Suh, N. P., "Pneumatic Suspension System with Independent Control of Damping, Stiffness, and Ride-Height," In Proceedings of ICAD2006, 4th International Conference on Axiomatic Design, Firenze, pp. 1-6, 2006.

13. Docquier, N., Fisette, P., and Jeanmart, H., "Multiphysic Modelling of Railway Vehicles Equipped with Pneumatic Suspensions," Vehicle System Dynamics 45, no. 6, pp. 505-524, 2007.

14. Docquier, N., Fisette, P., and Jeanmart, H., "Model-based Evaluation of Railway Pneumatic Suspensions," Vehicle System Dynamics 46, no. S1, pp. 481-493, 2008.

15. Kim, H., and Lee, H., "Height and Leveling Control of Automotive Air Suspension System Using Sliding Mode Approach," Vehicular Technology, IEEE Transactions, vol. 60, no. 5, pp. 2027-2041, 2011.

16. Chang, F., and Lu, Z., "Dynamic Model of an Air Spring and Integration into a Vehicle Dynamics Model," Proceedings of the Institution of Mechanical Engineers, Part D: Journal of Automobile Engineering 222, no. 10, pp. 1813-1825, 2008.

17. Richardson, S., Sandvik, A., Jones, C., Josevski, N., Pok, P. W., and Orton, T., "The Comparative Testing of a Single and Double Ride Height Control Valve Suspension Control Systems," 23rd International Technical Conference on the Enhanced Safety of Vehicles (ESV), no. 13-0292, 2013.

Page 27 of 30 
18. Hou, Y., Chen Y., and Ahmadian, M., "A Simulation-Based Study on the Improvement of Semi-Truck Roll Stability in Roundabouts,” no. 2016-01-8038, SAE Technical Paper, 2016.

19. Chen, Y., Ahmadian, M., and Peterson, A., "Pneumatically Balanced Heavy Truck Air Suspensions for Improved Roll Stability,” no. 2015-01-2749, SAE Technical Paper, 2015.

20. Richer, E., and Hurmuzlu, Y., "A High Performance Pneumatic Force Actuator System: Part I-Nonlinear Mathematical Model," Journal of Dynamic Systems, Measurement, and Control 122, no. 3, pp. 416-425, 2000.

21. Lee, S. J., "Development and Analysis of an Air Spring Model," International Journal of Automotive Technology, vol. 11, no. 4, pp. 471-479, 2011.

22. Nakajima, T., Shimokawa, Y., Mizuno, M., and Sugiyama, H., "Air Suspension System Model Coupled with Leveling and Differential Pressure Valves for Railroad Vehicle Dynamics Simulation,” Journal of Computational and Nonlinear Dynamics, vol. 9, no. 3, 2014.

23. Zhu, Z., "Flow Characterization and Redesign of Load-Leveling Valves for Improving Transient Dynamics of Heavy Truck Air Suspensions," Master thesis, Virginia Tech, 2016.

24. Chen, Y., Hou, Y., Peterson, A., and Ahmadian, M., "Failure Mode and Effects Analysis of Dual Leveling Valve Airspring Suspensions on Truck Dynamics," Vehicle System Dynamics, 2018. DOI: https://doi.org/10.1080/00423114.2018.1480787. 


\section{Appendix A}

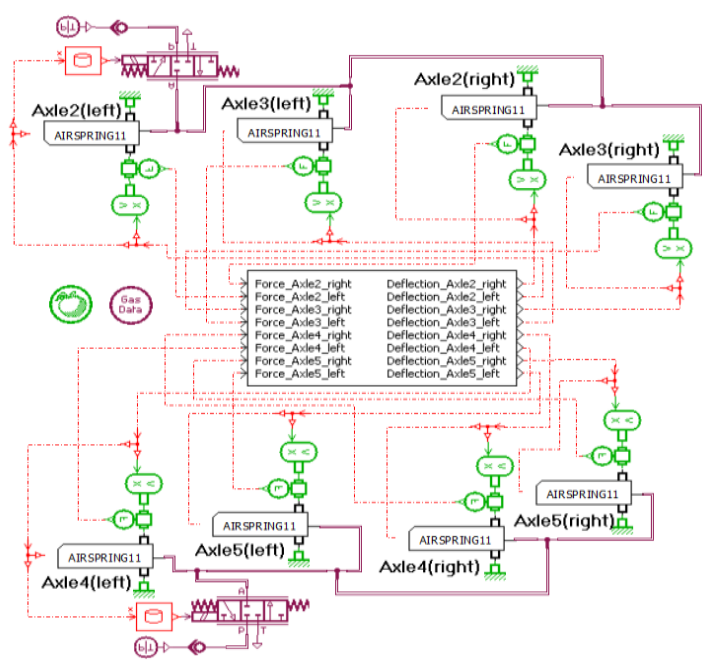

(a)

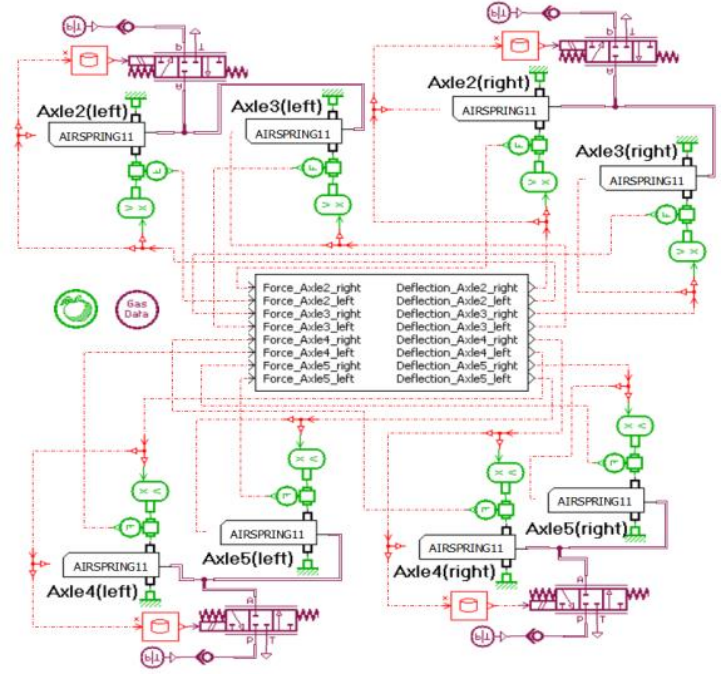

(b)

Figure 18. Pneumatic suspension models in AMESim: (a) OE and (b) balanced suspensions

\section{Appendix B}

Table 1. Parameters for the pneumatic suspension simulation

\begin{tabular}{|l|l|l|}
\hline Parameter & Value(English unit) & Value(SI unit) \\
\hline Air tank pressure & $120.0 \mathrm{psi}$ & $827370.9 \mathrm{pa}$ \\
\hline Atmospheric pressure & $14.7 \mathrm{psi}$ & $101300.0 \mathrm{pa}$ \\
\hline External temperature & $68 \mathrm{~F}$ & $293 \mathrm{~K}$ \\
\hline Hose inner diameter (Balanced) & $0.40 \mathrm{in}$ & $10.16 \mathrm{~mm}$ \\
\hline Hose inner diameter (OE) & $0.24 \mathrm{in}$ & $6.10 \mathrm{~mm}$ \\
\hline Hose absolute roughness & $0.000003 \mathrm{in}$ & $0.000076 \mathrm{~mm}$ \\
\hline Specific gas constant for dry air & $287.058 \mathrm{~J} /(\mathrm{kg}-\mathrm{K})$ & $53.353 \mathrm{lbf}-\mathrm{ft} /\left(\mathrm{lb}-{ }^{\circ} \mathrm{R}\right)$ \\
\hline Specific heat ratio & 1.38 & 1.38 \\
\hline The flow area of the check valve & $0.1550 \mathrm{in}^{2}$ & $0.0001 \mathrm{~m}$ \\
\hline Tractor airspring initial height & $11 \mathrm{in}$ & $279 \mathrm{~mm}$ \\
\hline Trailer airspring initial height & 8 in & $203 \mathrm{~mm}$ \\
\hline
\end{tabular}


Table 2. Parameters for the semi-trailer truck dynamic simulation

\begin{tabular}{|c|c|c|c|}
\hline Unit & Parameter & Value(English unit) & Value(SI unit) \\
\hline \multirow{26}{*}{ Tractor } & Longitudinal distance from the tractor CG to the steering axle & 75.7 in & $192.2 \mathrm{~cm}$ \\
\hline & The vertical distance from the tractor CG to the ground & 39.4 in & $100.0 \mathrm{~cm}$ \\
\hline & Tractor body mass (sprung mass) & $14892 \mathrm{lb}$ & $6755 \mathrm{~kg}$ \\
\hline & Roll inertia of sprung mass & $174715 \mathrm{lb}-\mathrm{ft}^{2}$ & $7363 \mathrm{~kg}-\mathrm{m}^{2}$ \\
\hline & Pitch inertia of sprung mass & $551591 \mathrm{lb}-\mathrm{ft}^{2}$ & $23244 \mathrm{~kg}-\mathrm{m}^{2}$ \\
\hline & Yaw inertia of sprung mass & $499365 \mathrm{lb}-\mathrm{ft}^{2}$ & $21043 \mathrm{~kg}-\mathrm{m}^{2}$ \\
\hline & Longitudinal distance from the fifth wheel to the steering axle & 199.0 in & $505.5 \mathrm{~cm}$ \\
\hline & The vertical distance from the fifth wheel to the ground & 43.3 in & $110.0 \mathrm{~cm}$ \\
\hline & Fifth-wheel roll freedom & $\pm 0.50 \mathrm{deg}$ & $\pm 0.50 \mathrm{deg}$ \\
\hline & Fifth-wheel pitch freedom & $-11.00 \sim 7.00 \mathrm{deg}$ & $-11.00 \sim 7.00 \mathrm{deg}$ \\
\hline & Fifth-wheel yaw freedom & $\pm 90.00 \mathrm{deg}$ & $\pm 90.00 \mathrm{deg}$ \\
\hline & Distance from the front drive axle to the steering axle & 186.0 in & $472.4 \mathrm{~cm}$ \\
\hline & Distance from the rear drive axle to the steering axle & 237.8 in & $604.0 \mathrm{~cm}$ \\
\hline & The track width of the steering axle & 83.6 in & $212.3 \mathrm{~cm}$ \\
\hline & Leaf spring stiffness on the steering axle & $1427.5 \mathrm{lb} / \mathrm{in}$ & $250.0 \mathrm{~N} / \mathrm{mm}$ \\
\hline & Damping coefficient on the steering axle & 97.4 lb-s/in & $17.1 \mathrm{kN}-\mathrm{s} / \mathrm{m}$ \\
\hline & The lateral spacing between leaf springs on the steering axle & 35.0 in & $88.9 \mathrm{~cm}$ \\
\hline & The lateral spacing between dampers on the steering axle & 43.3 in & $110.0 \mathrm{~cm}$ \\
\hline & The track width of the front drive axle & 72.6 in & $184.4 \mathrm{~cm}$ \\
\hline & Damping coefficient on the front drive axle & $177.0 \mathrm{lb}-\mathrm{s} / \mathrm{in}$ & $31.0 \mathrm{kN}-\mathrm{s} / \mathrm{m}$ \\
\hline & The lateral spacing between airsprings on the front drive axle & 30.0 in & $76.2 \mathrm{~cm}$ \\
\hline & The lateral spacing between dampers on the front drive axle & 42.0 in & $106.7 \mathrm{~cm}$ \\
\hline & The track width of the rear drive axle & 72.6 in & $184.4 \mathrm{~cm}$ \\
\hline & Damping coefficient on the rear drive axle & $177.0 \mathrm{lb}-\mathrm{s} / \mathrm{in}$ & $31.0 \mathrm{kN}-\mathrm{s} / \mathrm{m}$ \\
\hline & The lateral spacing between airsprings on the rear drive axle & 30.0 in & $76.2 \mathrm{~cm}$ \\
\hline & The lateral spacing between dampers on the rear drive axle & 42.0 in & $106.7 \mathrm{~cm}$ \\
\hline \multirow{11}{*}{ Trailer } & Trailer tare mass & $11358 \mathrm{lb}$ & $5152 \mathrm{~kg}$ \\
\hline & Trailer gross mass & $38401 \mathrm{lb}$ & $17418 \mathrm{~kg}$ \\
\hline & Trailer unsprung mass & $3043 \mathrm{lb}$ & $1380 \mathrm{~kg}$ \\
\hline & The vertical distance from the trailer CG to the ground & 106.2 in & $269.8 \mathrm{~cm}$ \\
\hline & The vertical distance from the kingpin to the ground & 43.3 in & $110.0 \mathrm{~cm}$ \\
\hline & Distance from the trailer front axle to the kingpin & 498.0 in & $1264.9 \mathrm{~cm}$ \\
\hline & Distance from the trailer rear axle to the kingpin & 546.0 in & $1386.8 \mathrm{~cm}$ \\
\hline & The track width of the trailer axles & 77.5 in & $196.9 \mathrm{~cm}$ \\
\hline & Damping coefficient on the trailer axles & $177.0 \mathrm{lb}$-s/in & $31.0 \mathrm{kN}-\mathrm{s} / \mathrm{m}$ \\
\hline & The lateral spacing between airsprings on the trailer axles & 39.4 in & $100.1 \mathrm{~cm}$ \\
\hline & The lateral spacing between dampers on the trailer axles & 31.5 in & $80.0 \mathrm{~cm}$ \\
\hline
\end{tabular}

